\title{
CRÓNICA PARLAMENTARIA DEL CONGRESO DE LOS DIPUTADOS
}

AURORA GUTIÉRREZ NOGUEROLES

Profesora Asociada de Derecho Constitucional UNED 



\title{
CRÓNICA PARLAMENTARIA DEL CONGRESO DE LOS DIPUTADOS
}

\author{
POR \\ AURORA GUTIÉRREZ NOGUEROLES \\ Profesora Asociada de Derecho Constitucional \\ UNED
}

Para seguir con el habitual informe sobre la actividad de la Cámara Baja, hemos de centrar esta vez nuestra atención en los periodos de sesiones tercero y cuarto de la VII Legislatura en curso, que comprenden entre ambos el año 2001 en su totalidad. Se hará, como es costumbre, una particular selección de lo que se considere de mayor interés entre la total actividad de dicha Cámara. Y también siguiendo los mismos criterios hasta ahora utilizados, hemos escindido nuestro análisis en los dos apartados habituales: la actividad legislativa y la actividad no legislativa.

\section{ACTIVIDAD LEGISLATIVA}

\section{LEYES}

\subsection{Leyes orgánicas}

Durante los períodos de sesiones analizados, han sido aprobadas siete leyes orgánicas, que son las que a continuación se relacionan:

- Ley Orgánica 1/2001, de 26 de marzo, por la que se modifica la Ley Orgánica 13/1982, de 10 de agosto, de reintegración y amejoramiento del Régimen Foral de Navarra (BOE núm. 75, de 28/03/2001). 
- Ley Orgánica 2/2001, de 28 de junio, sobre composición del Consejo General del Poder Judicial, por la que se modifica la Ley Orgánica 6/1985, de1 de julio, del Poder Judicial (BOE núm. 155, de 29/06/2001).

- Ley Orgánica $3 / 2001$, de 6 de noviembre, por la que se autoriza la ratificación por España del Tratado de Niza, por el que se modifican el Tratado de la Unión Europea, los Tratados constitutivos de las Comunidades Europeas y determinados actos conexos, firmado en Niza el día 26 de febrero de 2001 (BOE núm. 267, de 7/11/2001).

- Ley Orgánica 4/2001, de 12 de noviembre, reguladora del Derecho de Petición (BOE núm. 272, de 13/11/2001).

- Ley Orgánica 5/2001, de 13 de diciembre, complementaria a la Ley General de Estabilidad Presupuestaria (BOE núm. 299, de 14/12/2001).

- Ley Orgánica 6/2001, de 21 de diciembre, de Universidades (BOE núm. 307, de 24/12/2001).

- Ley Orgánica 7/2001, de 27 de diciembre, de modificación de la Ley Orgánica 8/1980, de 22 de septiembre, de Financiación de las Comunidades Autónomas (BOE núm. 313, de 31/12/2001).

\subsection{Leyes ordinarias}

En el transcurso de los referidos periodos de sesiones, han resultado aprobadas veinticuatro leyes ordinarias, que son las detalladas a continuación:

- Ley $1 / 2001$, de 13 de marzo, por la que se autoriza la participación del Reino de España en la octava reposición de recursos del Fondo Africano del Desarrollo (BOE núm. 64, de 15/03/2001).

- Ley 2/2001, de 26 de marzo, por la que se crea el Consejo General de Colegios Profesionales Dentales (BOE núm. 75, de 28/03/2001).

- Ley 3/2001, de 26 de marzo, de pesca marítima del Estado (BOE núm. 75, de 28/03/2001, y BOE núm. 174, de 21/08/2001, para corrección de erratas).

- Ley 4/2001, de 24 de abril, sobre concesión de un crédito extraordinario por importe de $\mathbf{1 5 . 5 6 0 . 6 2 5 . 0 0 0}$ pesetas, para compensar el déficit de la Compañía Transmediterránea, Sociedad Anónima, 
correspondiente al ejercicio de 1997, por la explotación de los servicios de comunicaciones marítimas de interés nacional y los ajustes por la finalización del contrato regulador de los referidos servicios (BOE núm. 99, de 25/04/2001).

- Ley 5/2001, de 8 de mayo, sobre concesión de un suplemento de crédito, por importe de 4.866 .309 .925 pesetas, para el pago de retribuciones establecidas en diversas sentencias firmes, falladas a favor de las personas encargadas de la enseñanza de la religión católica en los colegios públicos (BOE núm. 111, de 9/05/2001).

- Ley 6/2001, de 8 de mayo, de modificación del Real Decreto Legislativo 1302/1986, de 28 de junio, de evaluación de impacto ambiental (BOE núm. 111, de 9/05/2001).

- Ley 7/2001, de 14 de mayo, de modificación de la Ley del Patrimonio de Estado, Texto Articulado aprobado por Decreto 1022/1964, de 15 de abril (BOE núm. 116, de 15/05/2001).

- Ley 8/2001, de 4 de junio, sobre concesión de un crédito extraordinario por un importe de 13.858 .385 .705 pesetas, para atender insuficiencias de crédito producidas en el ejercicio de 1999 por las subvenciones que se efectúan para la cobertura de las diferencias de cambio de las divisas obtenidas en préstamos concedidos a las sociedades concesionarias de autopistas de peaje (BOE núm. 134, de $5 / 06 / 2001)$.

- Ley 9/2001, de 4 de junio, por la que se modifica la Disposición Transitoria Sexta de la Ley 54/1997, de 27 de noviembre, del Sector Eléctrico, determinados artículos de la Ley 16/1989, de 17 de julio, de Defensa de la Competencia y determinados artículos de la Ley 46/1988, de 17 de diciembre, sobre Introducción del Euro (BOE núm. 134 , de 5/06/2001).

- Ley 10/2001, de 5 de julio, del Plan Hidrológico Nacional (BOE núm. 161 , de 6/07/2001, y BOE núm. 184, de 2/08/2001, para corrección de errores).

- Ley 11/2001, de 5 de julio, por la que se crea la Agencia Española de Seguridad Alimentaria (BOE núm. 161, de 6/07/2001).

- Ley 12/2001, de 9 de julio, de medidas urgentes de reforma del mercado de trabajo para el incremento del empleo y su calidad (BOE núm. 164, de 10/08/2001).

- Ley 13/2001, de 9 de julio, sobre concesión de un crédito extraordinario, por importe de 8.229.849.001 pesetas, para atender al pago de obligaciones derivadas de la compensación a las Universidades 
públicas por la reducción o exención en los precios públicos por servicios académicos a alumnos de familias numerosas correspondientes a los cursos 1996-97 y 1997-98 (BOE núm. 164, de 10 de julio de 2001).

- Ley 14/2001, de 9 de julio, sobre concesión de dos créditos extraordinarios por importe total de 4.246.984.705 pesetas para el pago de las cantidades derivadas de la Sentencia del Tribunal Superior de Justicia de Andalucia, de 28 de diciembre de 1998, a los titulares de varias fincas expropiadas en el Parque Nacional de Doñana (BOE núm. 164, de 10/07/2001).

- Ley 15/2001, de 9 de julio, de fomento y producción de la cinematografía y del sector audiovisual (BOE núm. 164, de 10/07/2001).

- Ley 16/2001, de 21 de noviembre, por la que se establece un proceso extraordinario de consolidación y provisión de plazas de personal estatutario en las Instituciones Sanitarias de la Seguridad Social de los Servicios de Salud del Sistema Nacional de Salud (BOE núm. 280, de 22/11/2001).

- Ley 17/2001, de 7 de diciembre, de Marcas (BOE núm. 294, de $8 / 12 / 2001)$.

- Ley 18/2001, de 12 de diciembre, General de Estabilidad Presupuestaria (BOE núm. 298, de 13/12/2001, y BOE núm. 40, de $15 / 02 / 2002$, para corrección de errores).

- Ley 19/2001, de 19 de diciembre, de reforma del Texto Articulado de la Ley sobre Tráfico, Circulación de Vehículos a Motor y Seguridad Vial, aprobado por Real Decreto Legislativo 339/1990, de 2 de marzo (BOE núm. 308, de 20/12/2001).

- Ley 22/2001, de 27 de diciembre, reguladora de los Fondos de Compensación Interterritorial (BOE núm. 313, de 31/12/2001).

- Ley 23/2001, de 27 de diciembre, de Presupuestos Generales del Estado para el año 2002 (BOE núm. 313, de 31/12/2001).

- Ley 24/2001, de 27 de diciembre, de Medidas Fiscales, Administrativas y del Orden Social (BOE núm. 313, de 31/12/2001).

- Ley 25/2001, de 27 de diciembre, por la que se prorroga la vigencia del Concierto Económico con la Comunidad Autónoma del Pais Vasco, aprobado por Ley 12/1981, de 13 de mayo (BOE núm. 313, de $31 / 12 / 2001)$.

- Ley 26/2001, de 27 de diciembre, por la que se establece el sistema de infracciones y sanciones en materia de encefalopatias espongiformes transmisibles (BOE núm. 7, de 12/01/2002). 


\section{DECRETOS-LEYES}

En el transcurso de los dos periodos de sesiones antes referidos, han sido aprobados dieciséis Decretos-leyes, posteriormente convalidados, conforme a lo establecido en el artículo 62-CE, por el Pleno del Congreso de los Diputados. Son los que se detallan a continuación:

- Real Decreto-Ley 1/2001, de 19 de enero, por el que se aprueba la concesión de un aval a favor de la República de Argentina y se amplía el límite de aprobación de operaciones por el Consejo de Ministros con cargo al Fondo de Ayuda al Desarrollo (BOE núm. 18, de 20/01/2001; fecha de convalidación: 08/02/2001).

- Real Decreto-Ley 2/2001, de 2 de febrero, por el que se modifica la Disposición Transitoria Sexta de la Ley 54/1997, de 27 de noviembre, del Sector Eléctrico y determinados artículos de la Ley 16/1989, de 17 de julio, de Defensa de la Competencia (BOE núm. 30, de 03/02/2001; fecha de convalidación: 22/02/2001).

- Real Decreto-Ley 3/2001, de 9 de febrero, por el que se adoptan medidas para reparar los daños causados por las inundaciones producidas en la Comunidad Autónoma de Cataluña a consecuencia de las lluvias torrenciales (BOE núm. 36, de 01/02/2001; fecha de convalidación: 22/02/2001).

- Real Decreto-Ley 4/2001, de 16 de febrero, sobre el régimen de intervención administrativa aplicable a la valoración energética de harinas de origen animal, procedentes de la transformación de despojos y cadáveres de animales (BOE núm. 42, de 17/02/2001; fecha de convalidación: 15/03/2001).

- Real Decreto-Ley 5/2001, de 2 de marzo, de medidas urgentes de reforma del mercado de trabajo para el incremento del empleo y la mejora de su calidad (BOE núm. 54, de 03/03/2001, y BOE núm. 60, de 10/03/2001, para corrección de errores; fecha de convalidación: 15/03/2001).

- Real Decreto-Ley 6/2001, de 6 de abril, por el que se adoptan medidas urgentes para reparar los daños causados por las lluvias y temporales acaecidos desde los últimos días de octubre de 2000 hasta finales del mes de enero de 2001 en las Comunidades Autónomas de Galicia y Castilla y León (BOE núm. 84, de 07/04/2001; fecha de convalidación: 26/04/2001).

- Real Decreto-Ley 7/2001, de 6 de abril, por el que se adoptan medidas urgentes para reparar los daños causados por las lluvias e inun- 
daciones acaecidas durante los dias 21 a 26 de octubre de 2000 en las provincias de Tarragona, Zaragoza, Teruel, Castellón, Valencia y Murcia (BOE núm. 84, de 07/04/2001; fecha de convalidación: 26/04/2001).

- Real Decreto-Ley 8/2001, de 6 de abril, por el que se establece el sistema de infracciones y sanciones en materia de encefalopatías espongiformes transmisibles (BOE núm. 84, de 07/04/2001; fecha de convalidación: 26/04/2001).

- Real Decreto-Ley 9/2001, de 6 de abril, por el que se adoptan medidas adicionales en el marco de erradicación de las encefalopatías espongiformes transmisibles (BOE núm. 84, de 07/04/2001; fecha de convalidación: 26/04/2001).

- Real Decreto-Ley 10/2001, de 1 de junio, de adopción de medidas de carácter urgente para paliar los efectos producidos por las lluvias persistentes en determinados cultivos de la Comunidad Autónoma de Andalucía (BOE núm. 132, de 02/06/2001; fecha de convalidación: 21/06/2001).

- Real Decreto-Ley 11/2001, de 22 de junio, por el que se modifica el artículo 29 de la Ley 25/1988, de 29 de julio, de Carreteras y se establecen normas presupuestarias para atender los gastos derivados de actuaciones del Ministerio de Fomento en carreteras estatales (BOE núm. 150, de 23/06/2001; fecha de convalidación: 28/06/2001).

- Real Decreto-Ley 12/2001, de 29 de junio, por el que se aprueban medidas fiscales urgentes en materia de retenciones e ingresos a cuenta del Impuesto sobre la Renta de las Personas Físicas y del Impuesto sobre Sociedades (BOE núm. 156, de 30/06/2001, y BOE núm. 176, de 24/07/2001, para corrección de errores; fecha de convalidación: 26/07/2001).

- Real Decreto-Ley 13/2001, de 5 de septiembre, por el que se adoptan medidas urgentes para reparar los daños causados por los episodios de lluvias intensas acaecidos en los meses de febrero y marzo de 2001 en la Comunidad de Castilla y León (BOE núm. 214, de 06/09/2001; fecha de convalidación: 20/09/2001).

- Real Decreto-Ley 14/2001, de 28 de septiembre, por el que se establece el régimen del reaseguro por cuenta del Estado de los riesgos de guerra y terrorismo que pueden afectar a la navegación aérea (BOE núm. 234, de 29/09/2001; fecha de convalidación: $31 / 10 / 2001$ ). 
- Real Decreto-Ley 15/2001, de 2 de noviembre, por el que se adoptan medidas urgentes en materia de transporte aéreo (BOE núm. 264, de 03/11/2001; fecha de convalidación: 22/11/2001).

- Real Decreto-Ley 16/2001, de 27 de diciembre, de medidas para el establecimiento de un sistema de jubilación gradual y flexible (BOE núm. 313, de 31/12/2001; fecha de convalidación: 05/02/2002).

\section{DECRETOS LEGISLATIVOS}

Sólo una vez, a lo largo de los dos periodos de sesiones que se estudian, ha tenido el Gobierno la posibilidad, amparada en la previsión del artículo 82.1 de la Constitución española, de ejercitar, por delegación de las Cortes Generales, esa función tan típicamente normativa de elaborar textos articulados o refundidos. Fue, en particular, la Disposición Final $2 .^{\circ}$ de la Ley 46/1999, de 13 de diciembre, en la redacción dada por la Ley 6/2001, de 8 de mayo, de Evaluación de Impacto Ambiental, la que autorizó al Gobierno para que, en el plazo de dos años a partir de la entrada en vigor de esta última ley, refundiera y adaptara toda la normativa vigente sobre aguas. Asi pues, como concreto fruto de esta autorización, se elaboró y promulgó el Real Decreto Legislativo 1/2001, de 20 de julio, por el que se aprueba elTexto Refundido de la Ley de Aguas (BOE núm. 176, de 24/07/2001).

\section{PROPOSICIONES DE LEY}

En el transcurso de los dos períodos de sesiones analizados, han sido presentadas 104 proposiciones de ley, de las que fueron tomadas en consideración por el Pleno de la Cámara un total de 42 proposiciones, que, desglosadas en función del Grupo o Parlamento autor de la iniciativa, son las que a continuación se relacionan:

\section{a) Del Grupo Catalán}

- Reforma del Texto Articulado de la Ley sobre Tráfico, Circulación de Vehículos a Motor y Seguridad Vial, aprobado por Real Decreto Legislativo 339/1990, de 2 de marzo (fecha de presentación: 08/03/2001). 


\section{b) Del Grupo Federal Izquierda Unida}

- Modificación de la Ley 32/1999, de 8 de octubre, de Solidaridad con las Víctimas del Terrorismo (fecha de presentación: 22/03/2001).

- Modificación del Código Civil en materia de matrimonio (fecha de presentación: 05/04/2001).

- Modificación de la Ley 39/1995, de 19 de diciembre, de Organización del Centro de Investigaciones Sociológicas (fecha de presentación: 29/05/2001).

- (Orgánica) Modificación de la Ley Orgánica 6/1980, de 1 de julio, por la que se regulan los Criterios Básicos de la Defensa Nacional (fecha de presentación: 03/10/2001).

- Regulación del marco institucional de garantía del derecho constitucional a la comunicación (fecha de presentación: 22/11/2001).

c) Del Grupo Mixto

- Igualdad jurídica para las uniones de hecho (fecha de presentación: 18/04/2001).

- Modificación de la Ley Orgánica 10/1995, de 23 de noviembre, del Código Penal y de la Ley 14/1986, de 25 de abril, General de Sanidad (fecha de presentación: 17/05/2001).

- Equiparación de la situación de los trabajadores autónomos con la de los trabajadores que cotizan por el régimen general (fecha de presentación: 23/05/2001).

- Creación del Impuesto sobre Pernoctaciones en empresas turisticas de alojamiento (fecha de presentación: 21/06/2001).

- Modificación de la Ley 39/1999, de 5 de noviembre, para promover la conciliación de la vida familiar y laboral de las personas trabajadoras, con el fin de introducir un permiso de paternidad en los supuestos de parto (fecha de presentación: 21/06/2001).

- Modificación de la Ley 39/1988, de 28 de diciembre, reguladora de las Haciendas Locales (fecha de presentación: 27/09/2001).

- Modificación de la Ley 10/1995, de 23 de noviembre, del Código Penal, sobre los maltratos $y$ otras conductas que provoquen sufrimiento a los animales de compañía (fecha de presentación: 20/11/2001). 


\section{d) Del Grupo Popular}

- Modificación del artículo 28 delTexto Refundido de la Ley del Estatuto de los Trabajadores, aprobado por Real Decreto Legislativo 1/1995, de 24 de marzo (fecha de presentación: 12/02/2001).

- Modificación del Código Civil en materia de nacionalidad (fecha de presentación: 12/03/2001).

- Creación del Colegio Profesional de Pedagogos (fecha de presentación: 04/07/2001).

- (Orgánica) Reforma de la Ley Orgánica 10/1995, de 23 de noviembre, del Código Penal, de despenalización de la ocupación pacífica de inmuebles (fecha de presentación: 15/11/2001).

\section{e) Del Grupo Socialista}

- Retribuciones del personal de reserva procedente de reserva transitoria (fecha de presentación: 12/01/2001).

- Modificación del artículo 30.1.f) de la Ley 30/1984, de 2 de agosto, de Medidas para la Reforma de la Función Pública (fecha de presentación: 02/02/2001).

- Uso de las lenguas oficiales en la acuñación de monedas del euro (fecha de presentación: 08/02/2001).

- Exención de las bandas de música no profesionales de la tributación en el Impuesto sobre Actividades Económicas (fecha de presentación: 20/02/2001).

- Modificación del Código Civil en materia de nacionalidad (fecha de presentación: 20/02/2001).

- Tributación en el Impuesto sobre la Renta de No Residentes de los trabajadores temporeros (fecha de presentación: 28/02/2001).

- Tarifas y precios de los servicios postales (fecha de presentación: 15/03/2001).

- (Orgánica) Reforma de la Ley Orgánica 4/2000, de 11 de enero, sobre Derechos y Libertades de los Extranjeros en España y su integración social, en la redacción dada por la Ley Orgánica 8/2000, de 22 de diciembre (fecha de presentación: 23/03/2001).

- (Orgánica) Reforma de la Ley Orgánica 9/1983, de 15 de julio, reguladora del Derecho de Reunión (fecha de presentación: 23/03/2001). 
- Modificación de la Ley 32/1999, de 8 de octubre, de Solidaridad con las Víctimas del Terrorismo (fecha de presentación: 27/03/2001).

- Creación de la Agencia para la Igualdad de la Mujer en el Empleo (fecha de presentación: 05/04/2001).

- Modificación de determinados artículos de la Ley 39/1995, de 19 de diciembre, de Organización del Centro de Investigaciones Sociológicas (fecha de presentación: 09/04/2001).

- Modificación de la Ley 29/1998, de 13 de julio, reguladora de la Jurisdicción Contencioso-Administrativa, por la que se reconoce la legitimación activa de las organizaciones sindicales más representativas para interponer recurso de casación en interés de ley en el orden jurisdiccional contencioso-administrativo (fecha de presentación: 09/05/2001).

- Modificación de la Ley de Ordenación de la Edificación, para regular el certificado energético (fecha de presentación: 20/06/2001).

- (Orgánica) Reforma de la Ley Orgánica 5/1985, de 19 de junio, de Régimen Electoral General (fecha de presentación: 07/11/2001).

- Ampliación de derechos que posibiliten una real conciliación de la vida profesional y familiar de los trabajadores y trabajadoras (fecha de presentación: 14/11/2001).

- Inclusión del artículo 314 bis en el Código Penal, tipificando el acoso moral en el trabajo (fecha de presentación: 16/11/2001).

- Derecho a no sufrir acoso moral en el trabajo (fecha de presentación: 16/11/2001).

- (Orgánica) Modificación del Código Penal (fecha de presentación: 28/11/2001).

- (Orgánica) Integral contra la violencia de género (fecha de presentación: 13/12/2001).

\section{f) Del Grupo Vasco}

- Establecimiento de un impuesto sobre el vertido de residuos sólidos urbanos (fecha de presentación: 17/01/2001).

- Modificación de la Ley 32/1999, de 8 de octubre, de Solidaridad con las Víctimas del Terrorismo (fecha de presentación: 24/04/2001). 
g) Conjunta de los Grupos Izquierda Unida, Mixto, Socialista y Vasco

- Modificación de determinados artículos de la Ley 39/1995, de 19 de diciembre, de Organización del Centro de Investigaciones Sociológicas (fecha de presentación: 13/06/2001).

\section{h) Del Parlamento Catalán}

- Equiparación en deberes y derechos de los trabajadores autónomos y los trabajadores que cotizan por el régimen general (fecha de presentación: 23/11/2001).

- Modificación de la Ley 39/1988, de 28 de diciembre, reguladora de las Haciendas Locales, de actualización de la tasa por la utilización privativa o los aprovechamientos especiales constituidos en el suelo, subsuelo o vuelo de las vías públicas municipales (fecha de presentación: 23/11/2001). 